\title{
Cumhuriyet Dönemi Yabancı Eğitim Uzmanlarından John Dewey ve Beryl Parker’ın Raporlarında "İyi Vatandaş" Algısı
}

\author{
Ali YALÇIN ${ }^{1}$ \\ ${ }^{1}$ Eğitim Fakültesi, Uludağ Üniversitesi, Bursa, Türkiye
}

Sorumlu Yazar: Ali YALÇIN, aliylcnn77@gmail.com

Makale Türü: Araştırma Makalesi

Bilgilendirme: Bu makale, 30 Ekim-01 Kasım 2018 tarihleri arasında Çanakkale'de düzenlenmiş olan 2. Uluslararası Sosyal Bilimler Eğitimi Sempozyumunda sözlü bildiri olarak sunulmuştur.

Kaynak Gösterimi: Yalçın, A. (2019). Cumhuriyet dönemi yabancı eğitim uzmanlarından John Dewey ve Beryl Parker'ın raporlarında "iyi vatandaş" algısı. Eğitimde Kuram ve Uygulama, 15(Özel Sayı 1), 59-70. doi: 10.17244/eku.492197

\section{The Perception of "Good Citizen" in The Reports of John Dewey and Beryl Parker, Two of The Republic Period Foreign Education Experts}

\author{
Ali YALÇIN ${ }^{1}$ \\ ${ }^{1}$ Faculty of Education, Uludă̆ University, Bursa, Turkey
}

Corresponding Author: Ali YALÇIN, aliylcnn77@gmail.com

Article Type: Research Article

Acknowledgement: This article was orally presented as a paper at the 2nd International Symposium on Social Sciences Education organized between 30th October and 1st November in Çanakkale, Turkey.

To Cite This Article: Yalçın, A. (2019). Cumhuriyet dönemi yabancı eğitim uzmanlarından John Dewey ve Beryl Parker'ın raporlarında "iyi vatandaş" algısı. Eğitimde Kuram ve Uygulama, 15(Özel Sayı 1), 59-70. doi: 10.17244/eku.492197 
2019, 15(Özel Sayı 1), 59-70

\title{
Cumhuriyet Dönemi Yabancı Eğitim Uzmanlarından John Dewey ve Beryl Parker'ın Raporlarında "İyi Vatandaş" Algısı
}

\author{
Ali YALÇIN ${ }^{1}$ \\ ${ }^{1}$ Eğitim Fakültesi, Uludă̆ Üniversitesi, Bursa, Türkiye \\ ORCID: https://orcid.org/0000-0001-8421-3924
}

\begin{tabular}{|c|c|}
\hline Öz & Makale Bilgisi \\
\hline $\begin{array}{l}\text { Eğitimle ilgili tarihsel dokümanlar, belgeler ve raporlar, dönemin iyi ve nitelikli vatandaş } \\
\text { özelliklerinin nasıl olması gerektiği üzerine odaklanmıştır. Cumhuriyet döneminde, eğitim } \\
\text { ve öğretim faaliyetlerinin niteliğini arttırmak için birçok yabancı eğitim uzmanı } \\
\text { Türkiye'ye gelmiştir. Özellikle, } 1923-1960 \text { yılları arasında farklı ülkelerden yabancı } \\
\text { eğitim uzmanları, ülkemize davet edilmiş ve Türk eğitim sisteminin sorunlarına çözüm } \\
\text { üretmek amacıyla birçok rapor hazırlanmıştır. Yabancı uzmanların bu raporlarında, } \\
\text { sunmuş oldukları çözüm önerileriyle Türk eğitim yapısı üzerinde önemli etkiler bıraktığ1 } \\
\text { söylenebilir. Özellikle bu uzmanlar raporlarında, iyi vatandaş özelliklerinin nasıl olması } \\
\text { gerektiği ve bununla birlikte nitelikli bir insan yetiştirmenin nasıl olması gerektiğine dair, } \\
\text { birtakım önemli görüş ve öneriler belirtmişlerdir. Özellikle, John Dewey, Türk eğitim } \\
\text { sisteminin genel yapısı üzerine, Beryl Parker ise ilköğretim alanında rapor sunmuştur. Bu } \\
\text { yabancı eğitim uzmanları, hazırlamış oldukları raporlarda, eğitim sistemiyle ilgili önemli } \\
\text { tespitler yapmışlardır. Bu nedenle araştırmanın amacı; Cumhuriyet dönemi yabancı eğitim } \\
\text { uzmanlarından John Dewey ve Beryl Parker'ın raporlarında iyi vatandaş algısını tespit } \\
\text { etmektir. Bu bağlamda çalışmada, nitel araştırma yöntemlerinden dokuman incelenmesi } \\
\text { yöntemi kullanılmıştır. Araştırmanın veri kaynağı, John Dewey ve Beryl Parker'ın } \\
\text { raporlarından oluşmaktadır. Bu raporlardan elde edilen veriler, içerik analizine dayalı } \\
\text { olarak kodlanıp kategori haline getirilmiştir. Bunun sonucunda kategorileşen veriler, } \\
\text { yorumlanmıştır. Araştırmanın bulguları iki alan uzmanı tarafından kontrol edilerek }\end{array}$ & $\begin{array}{l}\text { Anahtar Kelimeler: Eğitim } \\
\text { Sistemi, Yabancı Uzmanlar, İyi } \\
\text { Vatandaş, Algı. } \\
\text { Makale Geçmişi: } \\
\text { Geliş: } 04 \text { Aralık } 2018 \\
\text { Düzeltme: } 22 \text { Aralık } 2018 \\
\text { Kabul: } 11 \text { Mart } 2019 \\
\text { Makale Türü: Araştırma } \\
\text { Makalesi }\end{array}$ \\
\hline
\end{tabular}




\begin{abstract}
Historical documents, papers and reports on education focused on how good and wellqualified citizens should be. During the Republican era, many foreign education experts came to Turkey in order to improve the quality of our education system. Particularly, between 1923 and 1960, foreign education experts from different countries were invited to our country and many reports were prepared in an attempt to solve the problems of the Turkish education system. It is possible to say that in these reports of foreign experts, they made a significant impact on the structure of the Turkish education system with the solutions they offered. Specifically, these experts identified some important opinions and recommendations in their reports on how good citizens should be and how to raise a wellqualified person. In particular, John Dewey reported on the general structure of the Turkish education system and Beryl Parker on the structure of primary school education. In their reports, these foreign education experts identified significant issues about the education system in Turkey. Therefore, the aim of the present study is to reveal the perception of good citizens mentioned in the reports of John Dewey and Beryl Parker, two of the foreign education experts in the Republican period. In this context, the method of document analysis, one of the qualitative research methods, was used in the study. The data source of the study consisted of the reports of John Dewey and Beryl Parker. The data obtained from these reports were coded and categorized based on content analysis. As a result, the data that was categorized was interpreted. The findings of the study were checked by two field experts and attempts were exerted to increase the validity and reliability of the study.
\end{abstract}

\section{Article Info}

Keywords: Turkish Education System, Foreign Experts, Good Citizen, Perception.

\section{Article History:}

Received: 04 December 2018

Revised: 22 December 2018

Accepted: 11 March 2019

Article Type: Research Article 


\section{Giriş}

Cumhuriyet döneminde kalkınma ve ilerleme sürecinde yaşanan bilgi ve teknik anlamdaki yetersizliğin giderilmesi noktasında, yabancı eğitim uzmanlarından faydalanma yoluna gidilmiştir. Özellikle nitelikli ve donanımlı insan yetiştirmek için Mustafa Kemal Atatürk’ün direktifleriyle çağdaş ülkelerin eğitim uzmanlarından faydalanılmıştır. Bilindiği gibi herhangi bir ülkenin siyasi, sosyal, kültürel ve ekonomi alanında gelişebilmesi için eğitime ihtiyaç duyulmaktadır. $\mathrm{Bu}$ nedenle ülkeler, yetiştirmek istedikleri bireylerin donanımlı ve nitelikli olmasına önem vermektedirler.

Vatan kavramı, yaklaşım ve algılayış bakımdan tarihsel bir değişim geçirmiştir. Bu kavram "nasıl bir vatandaş" sorusuna yanıt verebilecek sosyo-kültürel bir ayrıntıyı beraberinde getirmiştir. Genel olarak vatan, devletin hâkimiyet alanı ve sınırlarını meydana getiren toprak parçası olarak tanımlandığı söylenebilir. Özellikle eğitim sistemimiz, insan haklarına saygılı vatandaşlar yetiştirmeyi, Türk Milli Eğitimi’nin genel amaçları içinde düşünmüştür (Doğan, 2004). Bu bağlamda, geçmişten günümüze dünyada meydana gelen gelişmeler sonucunda, "vatandaş" kavramının önem kazanması ile birlikte toplumun ihtiyaçlarına yanıt verecek nitelikli insan yetiştirmenin önemi ortaya çıkmıştır.

İyi vatandaş kavramı, dönemin koşulları, siyasi yapı ve sosyo-kültürel etkenlere bağlı olarak şekillendiği söylenebilir. Bu bağlamda, Cumhuriyetten itibaren Türkiye' de eğitimin kalitesini arttırmak için hem öğretmenin iyi ve nitelikli yetişmesi hem de dönemin genel eğitim sistemi üzerine raporlar yazan birçok yabancı eğitim uzmanı, Türkiye'ye gelmiştir. Özellikle 1923-1960 yılları arasında, yani Atatürk-Milli Şef (1923-1950) dönemlerinde 79 kişi ve Demokrat Parti (1950-1960) döneminde ise 44 kişi olmak üzere toplam 123 yabancı eğitim uzmanı Türkiye'ye gelmiştir (Şahin, 1996; Budak, 2010). Bu eğitim uzmanları içerisinde John Dewey genel eğitim sistemi üzerine, Beryl Parker ise ilk tahsil hakkındaki raporu, bunlardan sadece birkaçıdır. Türkiye'ye davet edilen ilk eğitim uzmanlarından olan John Dewey, dönemin maarif vekilliğine iki rapor sunmuştur. Bu raporlar 1939 yılında yayınlanmıştır (Bal, 1991). John Dewey, nitelikli ve donanımlı bir vatandaş yetiştirilmesi noktasında, ilgili raporunda hem öğretmen niteliği hem de Türk eğitim yapısı ile ilgili önemli çözüm önerileri sunduğu söylenebilir. Öte yandan Türk eğitim sisteminin ilköğretim yapısı üzerine yapıcı çözüm önerileri sunan Beryl Parker, ilkokul, öğrenci, öğretmen, köy okulları ve ders programları alanında rapor sunmuştur (Dewey, 1939; Parker, 1939). Özellikle bu iki yabanc1 eğitim uzmanın raporunda yer alan konu başlıklarının içeriği incelendiğinde, iyi bir vatandaşın nasıl olması gerektiğine dair birtakım özelliklerin yer aldığı söylenebilir. Bu bağlamda bazı tarihi belgeler, raporlar ve dokümanlar, dönemin iyi vatandaş özelliklerini anlama noktasında son derece önemli bilgi kaynaklarıdır. Literatür incelendiğinde, öğretmen eğitiminde yabancı uzmanların etkisi (Şahin, 1996), Atatürk dönemi yabancı uzmanlar (Ortak, 2004), iyi vatandaş algısı, vatandaş eğitimi, iyi insan iyi vatandaş, bana göre iyi vatandaş, ders kitaplarında iyi vatandaş ve öğrencinin iyi vatandaş algısı üzerine (Civek, 2008; Dynneson, 1992; Ersoy, 2012; Kılınç, 2014; Kızılay, 2015; Osmanoğlu \& Öztürk, 2012; Prior, 1999; Yeşilbursa, 2015), farklı araştırmaların yapıldığı görülmektedir. Nitekim eğitim sistemi ile ilgili tarihsel dokümanlar ve raporlarda iyi vatandaşın nasıl olduğuna dair çalışmaların, yapılan literatür taramasından eksik olduğu saptanmıştır. Bu nedenle bu araştırmanın temel problemi, Cumhuriyet dönemi yabancı eğitim uzmanlarından John Dewey ve Beryl Parker'in raporlarında iyi vatandaş algısıdır.

\section{Araştırmanın Amacı}

Cumhuriyet dönemi Türkiye'ye gelen yabancı eğitim uzmanlarının raporlarında, nitelikli ve donanımlı bir vatandaşın nasıl olması gerektiği konusunda önemli öneriler sunulmuştur. Özellikle eğitim alanında tarihsel dokümanlar, ders kitapları ve eğitim programları, makbul bir vatandaşın nasıl olması gerektiği üzerine odaklanmaktadır. Bu bağlamda araştırmanın temel amacı, Cumhuriyet döneminde Türkiye'ye gelen yabancı eğitim uzmanlarından John Dewey ve Beryl Parker'in raporlarında iyi vatandaş algısını saptamaktır.

\section{Yöntem}

\section{Araştırmanın Deseni}

Nitel araştırma desenlerinde, bazı konuları daha iyi anlamak için geçmişe doğru giderek bazı olayları geçmişte var olduğu şekliyle betimlenmeye çalışıldığı söylenebilir (Karasar, 2012). Böylece nitel araştırmacılar, insanların deneyimlerini nasıl yorumladıklarını, dünyalarını nasıl kurduklarını, deneyimlerine nasıl bir anlam yüklediklerini 
anlamaya çalışırlar (Merriam, 2013). Bu nedenle problemin tanımlanması ve sınırlandırılmasına katkı sağlamak için araştırma tarihsel bir perspektife yerleştirilerek bilgiler birbiriyle ilişkilendirilebilir (Balc1, 2010). Bu bağlamda bu araştırma, tarihsel raporlara dayalı, iyi vatandaş algısını incelediği için araştırmada veri toplama aracı olarak nitel araştırma yöntemlerinden doküman incelemesi kullanılmıştır. Araştırmada veri kaynağı olarak kullanılan raporlar, aşağıda sunulmuştur.

- Dewey, J. (1939). Türkiye Maarifi Hakkında Rapor, İstanbul: Devlet Basımevi

- Parker, B. (1939). Türkiye'de İlk Tahsil Hakkında Rapor, İstanbul: Devlet Basımevi

\section{Verilerin Analizi}

Araştırmanın amacına uygun olarak doküman incelemesi ile elde edilen veriler, içerik analizine dayalı olarak çözümlenmiştir. Veri analizi yapılırken anlam dışarıya aktarılır. Bu bağlamda insanların ne söylediğini, araştırmacının ne gördüğünü ve ne okuduğunu birleştirme, indirgeme ve yorumlamayı içerir (Merriam, 2013). İçerik analizi sistematik sınıflandırma süreci içerisinde metin verilerinin içeriğini, temaları ve örüntülerini kodlayıp belirtir (Yıldırım \& Şimşek, 2012). Bu nedenle kategori oluşturma, aslında bir veri analizidir. Özellikle doküman okuduğumuz süre boyunca elde edilen notlar, yorumlar ve gözlemler bir nevi veri birleşenleri olarak adlandırılan kodlamalar olduğu söylenebilir (Merriam, 2013). Bu kodlamalar neticesinde oluşan kategoriler, birçok özgün örneği kapsayan ve birbirleriyle ilişki kuran kavramsal öğeler meydana getirir (Merriam, 2013, s. 173). Bu araştırmada yapılan analizler sonucunda bazı kodlamalar oluşmuş, bunun neticesinde bu kodlara dayalı olarak kategoriler meydana gelmiştir. Özellikle ilgili alan yazın taramasında çalışmaların analizine dayalı olarak çeşitli kategorilerin oluştuğu söylenebilir. Bu nedenle çalışmada yapılan analizler sonucunda toplam 6 kategori ortaya çıkmışıı. Araştırmanın geçerlilik ve güvenirliğini arttırmak için araştırmacı, kategorileri oluşturma ve metin kodlama sürecini yalnız yürüterek nitel veriler bir araya getirildikten sonra kod ve kategoriler alanında ilgili iki uzman görüşü alınarak analiz sürecinin geçerlik ve güvenirliği sağlanılmaya çalışılmıştır. Ayrıca yapılan analizler sonucunda elde edilen kodlar, ilgili kategoriler altında doğrudan verilmiştir.

\section{Bulgular}

$\mathrm{Bu}$ bölümde, araştırmada yapılan analizler sonucunda bazı kodlamalar oluşmuş, bunun neticesinde bu kodlara dayalı olarak toplam 6 kategori meydana gelmiştir. Bunlar Şekil 1'de gösterilmiştir.

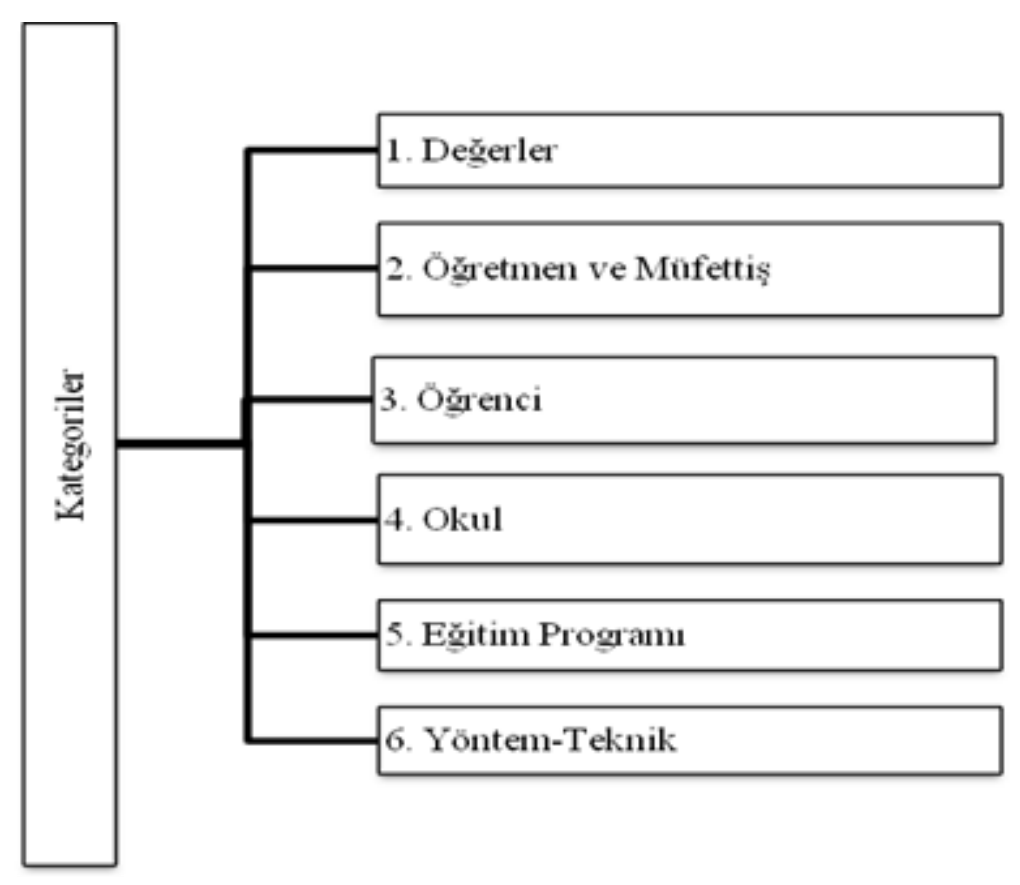

Şekil 1. Kategoriler. 


\section{Değerler Kategorisi}

\section{Berly Parker'ın Raporu}

$\sqrt{ }$ Vatandaşlık terbiyesi $\sqrt{ }$ İyilik

$\checkmark$ Vatana bağlilık $\quad \sqrt{ }$ Hoş

$\checkmark$ Sorumluluk

$\checkmark$ Dostluk

$\checkmark$ İstekli olma

$\checkmark$ Liyakat

$\sqrt{ }$ Çalışkanlık

$\checkmark$ Görev bilinci

$\sqrt{ }$ Vatan ve millete bağlllık

$\sqrt{ }$ Yardim etmek

$\checkmark$ Meslek ruhu

$\checkmark$ Alaka

$\sqrt{ }$ Çabalamak

$\checkmark$ Milli canlılık

$\sqrt{ }$ Temizlik

$\checkmark$ İşbirliği

$\checkmark$ Terbiye etmek

$\checkmark$ Cesaret

$\checkmark$ Milli hizmet

$\sqrt{ }$ Mesleki ahlak ve güven

\section{John Dewey'ın Raporu}

$\checkmark$ İyilik

$\checkmark$ Kabiliyet

$\checkmark$ Fedakârlık

$\checkmark$ Temizlik

$\checkmark$ İsraf etmemek $\sqrt{ }$ Dayanışma

$\sqrt{ }$ İşbirliği

$\sqrt{ }$ Yardımlaşma

$\checkmark$ Çalışkanlık

$\sqrt{ }$ Sorumluluk

Değerler kategorisine bakıldığında, Beryl Parker ve John Dewey'in raporlarında iyi vatandaş özelliklerini yansıtan temalara yer verilmiştir. Burada sorumluluk, çalışkanlık, yardımlaşma, kabiliyet, işbirliği adlı değerlere temas edildiği söylenebilir. Özellikle Parker'ın raporunda değerlere daha çok vurgu yapıldığı görülmektedir. Bunun nedeni Beryl Parker'ın raporu daha çok ilkokula yönelik önerilerinin olması ve çocukların bulunduğu yaş dönemlerinden kaynaklanıyor olabilir.

\section{2. Öğretmen ve Müfettiş Kategorisi}

\section{Berly Parker'ın Raporu}

$\sqrt{ }$ Nitelikli muallim

$\sqrt{ }$ Muallimin

$\sqrt{ }$ Meslek ruhu

$\sqrt{ }$ İşbirliği becerisi

$\sqrt{ }$ Teftiş

$\sqrt{ }$ Etkin denetim

$\sqrt{ }$ Çeşitli metotları

kullanma

$\sqrt{ }$ Vatanperver

muallimler

$\sqrt{ }$ Rehberlik yapma

$\checkmark$ Mesleklerine bağl1

olma

$\sqrt{ }$ Ders planı yapma değerlendirme becerisi

$\checkmark$ İş ve metotlarını ıslah etmek

$\checkmark$ İşini layıkıyla yapan

$\checkmark$ Milli konularda

hassasiyet

$\checkmark$ Talebe faaliyetlerini

arttırmas1

$\sqrt{ }$ Muallimin görev bilinci

$\sqrt{ }$ Birlik ve beraberlik

$\sqrt{ }$ İyi yetişmiş bir müfettiş

$\sqrt{ }$ Mesleki ahlak

$\sqrt{ }$ Güven

\section{John Dewey'm Raporu}

$\sqrt{ }$ Muallimin kabiliyeti

$\sqrt{ }$ İşbirliği

$\sqrt{ }$ Mütalea cemiyetleri

$\checkmark$ Komisyon işbirliği

$\sqrt{ }$ Muallimin deneyimi

$\sqrt{ }$ Mukayeseli tetkikat

$\sqrt{ }$ Müfettişlerin

yetiştirilmesi

$\sqrt{ }$ Muallimin ders becerisi

$\sqrt{ }$ Plan yapma $\checkmark$ Rehberlik ve yönlendirme $\sqrt{ }$ Zeki ve fedakâr muallimler

$\sqrt{ }$ Mesleki seviye

$\sqrt{ }$ Muallim-çevre işbirliği

$\sqrt{ }$ Tekemmül ve inkişaf etme

$\checkmark$ Tedris vesaiti

$\sqrt{ }$ Uygulamalı mesleki tatbikat

$\sqrt{ }$ Birlik ve beraberlik

$\sqrt{ }$ Mesleğini sevme

Öğretmen ve müfettiş kategorisi incelendiğinde, her iki yabancı eğitim uzmanının raporunda en çok üzerinde durulan konu, öğretmen yetiştirme ve müfettiş olduğu söylenebilir. Özellikle Türk eğitim sisteminin nitelikli, donanımlı ve iyi vatandaş yetiştirme noktasında öğretmen ve denetleme mekanizmasının son derece önemli olduğu yorumlanabilir. Beryl Parker'ın raporunda yer alan kodlara bakıldığında, nitelikli öğretmen, görev bilinci, etkin denetleme, işbirliği becerisi, mesleğini sevme gibi temalara vurgu yaptığı saptanmıştır. John Dewey'in raporunda ise muallimin deneyimi, müfettiş yetiştirme, mesleğini sevme ve mesleği uygulama, işbirliği adlı temalara değinildiği 
söylenebilir. Her iki yabancı eğitim uzmanının raporunda yer alan temalar, işbirliği, müfettiş mekanizması, muallimin görev bilinci, birlik ve beraberlik, rehberlik ve mesleğini sevme adlı temaların ortak olduğu saptanmıştır.

\section{3. Öğrenci Kategorisi}

\section{Berly Parker'ın Raporu}

$\sqrt{ }$ Talebenin iyi eğitim $\quad \sqrt{ }$ Öğrenci kabiliyeti almas1

$\sqrt{ }$ İhtiyaçların $\quad \sqrt{ }$ Kabiliyet

karşılanması

$\checkmark$ Okuma $\quad \sqrt{ }$ Sanatsal faaliyetler

$\sqrt{ }$ İyi yetişmiş nitelikli $\quad \sqrt{ }$ Vatandaşlık terbiyesi

insan

$\checkmark$ İstekli talebe

$\sqrt{ }$ Çalışkan talebe

$\checkmark$ Talebenin başarısı

$\checkmark$ Grup faaliyetlerine

katılma

$\sqrt{ }$ Terbiyeli yetiştirme $\quad \sqrt{ }$ İlgi

$\sqrt{ }$ Bireysel farkl111klar

$\sqrt{ }$ Davranış

\section{John Dewey’ın Raporu}

\begin{tabular}{|c|c|}
\hline$\checkmark$ Yaparak yaşayarak & $\sqrt{ }$ Etkin vatandaş \\
\hline $\begin{array}{l}\sqrt{ } \text { Çocukların tedris } \\
\text { usulleri }\end{array}$ & $\sqrt{ }$ Kat1limc1 \\
\hline $\begin{array}{l}\sqrt{ } \text { Gerçek yaşamla bağ } \\
\text { kurma }\end{array}$ & $\sqrt{ }$ Toplumsallaşma \\
\hline$\sqrt{ }$ İlgi ve alaka & $\sqrt{ }$ Yönetme ve uygulama \\
\hline$\sqrt{ }$ Kabiliyet & $\sqrt{ }$ Yetenek \\
\hline $\begin{array}{l}\sqrt{ } \text { Nitelikli ve } \\
\text { donanımlı vatandaş }\end{array}$ & $\sqrt{ }$ Milli terbiye ve bilinç \\
\hline $\begin{array}{l}\sqrt{ } \text { Sanat ve el işlerinde } \\
\text { mütehassis }\end{array}$ & $\sqrt{ }$ Başarmak \\
\hline
\end{tabular}

Öğrenci kategorisi değerlendirildiğinde, Beryl Parker ve John Dewey’in raporlarında iyi vatandaşın niteliklerini yansıtan bulgulara ulaşıldığı söylenebilir. Beryl Parker raporunda, talebenin eğitimi, terbiye, kabiliyet, bireysel farklılık, istekli ve çalışkan talebe adlı temalara vurgu yapıldığı yorumlanabilir. John Dewey'in raporunda ise yaparak yaşayarak, kabiliyet, nitelikli ve donanımlı vatandaş, terbiye, başarı gibi temalara değinilmiştir. Özellikle her iki yabancı eğitim uzmanın raporunda, öğrencinin iyi bir eğitim alması, yeteneği, çalışkanlı̆̆ı, sanatsal faaliyetlere katılımı, terbiye adlı temaların benzer olduğu saptanmıştır. Ayrıca Beryl Parker, raporunda öğrencinin bireyselliği üzerinde dururken John Dewey ise raporunda öğrencinin toplumsallaşmasına vurgu yaptığı söylenebilir.

\section{Okul Kategorisi}

\section{Berly Parker'ın Raporu}

$\sqrt{ }$ Okulun imkânları $\quad \sqrt{ }$ Binaların muhafazası

$\begin{array}{ll}\sqrt{ } \text { Fiziki yapısı } & \sqrt{ } \text { Teçhizatı } \\ \sqrt{ } \text { Okulun muhiti } & \sqrt{ } \text { Okul işbirliği }\end{array}$

$\sqrt{ }$ Okul-içtimai ilişkisi $\quad \sqrt{ }$ Sınıf yapısı ve planı

$\sqrt{ }$ Eski binalar $\quad \sqrt{ }$ İktisatl kullanma

\section{John Dewey'ın Raporu}

\begin{tabular}{|c|c|}
\hline $\begin{array}{l}\sqrt{ } \text { Okulun nitelikli } \\
\text { insan yetiştirmede } \\
\text { önemi }\end{array}$ & $\begin{array}{l}\sqrt{ } \text { Mektebin ruhi ve } \\
\text { manevi muhiti }\end{array}$ \\
\hline $\begin{array}{l}\sqrt{ } \text { Okul kendini } \\
\text { yenilemeli }\end{array}$ & $\sqrt{ }$ Okul-aile işbirliği \\
\hline $\begin{array}{l}\sqrt{ } \text { Fikri intibah kadar } \\
\text { sinai intibahın da } \\
\text { merkezi }\end{array}$ & $\sqrt{ }$ Okulun ihtiyacı \\
\hline $\begin{array}{l}\sqrt{ } \text { Okul yaşam ve } \\
\text { deneyimin merkezi }\end{array}$ & $\begin{array}{l}\sqrt{ } \text { Okulun amac1, hedefi, } \\
\text { gayesi }\end{array}$ \\
\hline$\sqrt{ }$ Donanımlı yapıs1 & $\begin{array}{l}\sqrt{ } \text { Okul-talebe-gerçek } \\
\text { yaşam }\end{array}$ \\
\hline$\sqrt{ }$ Okul kütüphaneleri & $\begin{array}{l}\sqrt{ } \text { Yeterli miktarda } \\
\text { vatandaş yetiştirmek }\end{array}$ \\
\hline
\end{tabular}

Okul kategorisi incelendiğinde, her iki yabancı eğitim uzmanı raporlarında okulun, iyi ve nitelikli bir vatandaş yetiştirme noktasında ne kadar önemli olduğunu belirtmişlerdir. Beryl Parker ve John Dewey okul kategorisinde, okulun imkânları, donanımı, okul-toplum ilişkisi üzerine odaklandığı söylenebilir. Özellikle Dewey, okul-talebegerçek yaşam arasındaki bağa vurgu yapması, son derece önemli olduğu yorumlanabilir. Çünkü iyi ve nitelikli vatandaş, okulda öğrendiği bilgileri yaşamında uygulayan ve toplumda var olan sorunlara çözüm üretmek amaciyla 
hareket edendir. $\mathrm{Bu}$ nedenle okulun vatandaş yetiştirmede, temel bir felsefesi, amac1 ve hedefi olması gerektiği söylenebilir. Parker, raporunda daha çok okulun fiziksel yapısı üzerine görüş belirtmiştir. Ayrıca okulu, iktisatlı yani tasarruflu kullanma konusuna da vurgu yapıldığı saptanmıştır. John Dewey ise raporunda okulun, gerçek yaşamın ve deneyimin merkezi olması gerektiği noktasında, fikirler öne sürmüştür.

\section{Eğitim Programı Kategorisi}

\section{Berly Parker'ın Raporu}

$\begin{array}{ll}\sqrt{ } \text { Eğitimin niteliği } & \sqrt{ } \text { Eğitim laboratuvarları } \\ \sqrt{ } \text { Talebenin ihtiyaçları } & \sqrt{ } \text { Vatandaşlık eğitimi } \\ \begin{array}{l}\text { ve gelişimi } \\ \sqrt{ } \text { İyi program }\end{array} & \sqrt{ } \text { Toplumsal ruh } \\ \sqrt{ } \text { Planlı program } & \sqrt{ } \text { Öğrenci başarısı } \\ \sqrt{ } \text { Programın } & \\ \text { uygulanması } & \end{array}$

\section{John Dewey'ın Raporu}

$\sqrt{ }$ Devamlı bir inkişaf $\quad \sqrt{ }$ Planlı ve yönlendirici program1 $\sqrt{ }$ Tedrici ve mütekâmil bir program $\sqrt{ }$ Karşılaştırmalı eğitim program

$\checkmark$ Okul-program ve planlama

$\checkmark$ Programda yenilik

Eğitim programı kategorisi değerlendirildiğinde, Beryl Parker raporunda eğitimin niteliği, iyi ve planlı bir program, vatandaşlık eğitimi adlı temalara vurgu yapıldığı saptanmıştır. John Dewey’in raporunda ise programın sürekliliği, programda yenilik, planlı ve yönlendirici program gibi konulara değinildiği yorumlanabilir. Her iki yabancı eğitim uzmanın raporlarında planlı bir program ve uygulamalı bir programa vurgu yapıldığı söylenebilir. Beryl Parker ve John Dewey'in raporlarında, eğitim programı kategorisine yönelik iyi vatandaş özelliklerinin en az yer aldığı kategori olmuştur. Özellikle bu kategoriye yönelik kodlamaların az olmasının sebebi John Dewey’in daha çok öğretmen eğitimi ve genel eğitim sistemine yönelik önerilerinin olmasından olabilir. Ayrıca Beryl Parker'ın raporu da daha çok ilkokul eğitim sisteminde öğrenci, okul ve öğretmen konuları üzerine odaklandığı için eğitim programına yönelik temalara daha az vurgu yapıldığı söylenebilir.

\section{Yöntem-Teknik Kategorisi}

\section{Berly Parker'ın Raporu}

\section{$\checkmark$ Çeşitli yöntem ve \\ tekniklerin işe}

$\checkmark$ Eğitim usulleri

koşulması

$\sqrt{ }$ Öğrenme ortam1

$\sqrt{ }$ Uygulanan usuller

$\sqrt{ }$ Çocukluk ve gençlik tabiat1

$\sqrt{ }$ Yenilik yapma

$\sqrt{ }$ Model

$\sqrt{ }$ Kurs

$\sqrt{ }$ Sergi

$\checkmark$ Neşriyat

$\sqrt{ }$ Harita

$\sqrt{ }$ Grupla öğretim

$\sqrt{ }$ El yazis1

$\sqrt{ }$ Muallimin takriri

$\sqrt{ }$ Laboratuvar

$\checkmark$ Kitap ve mücerret

$\checkmark$ Tahlil ve tecrübe

$\sqrt{ }$ Muhakeme $\sqrt{ }$ İçtimai teknikler

$\checkmark$ Kütüphane tanzimi

$\sqrt{ }$ Yaşama yakınlık

\section{John Dewey'ın Raporu}

$\begin{array}{ll}\sqrt{ } \text { Araç-gerecin etkin } & \sqrt{ } \text { Ders öğretiminde } \\ \text { kullanımı } & \text { teknik ve yöntem }\end{array}$

$\sqrt{ }$ Kitap

$\sqrt{ }$ Tedris vasitaları

$\checkmark$ Asri ve fenni usullerle neşredilmesi

$\sqrt{ }$ Derste katılimc1 olmak

$\sqrt{ }$ Mütekâmil tedris usulleri

$\checkmark$ Deneyim

$\sqrt{ }$ Uygulama yapılması

$\checkmark$ Tedris usullerine ait derslerin intihabı

$\sqrt{ }$ Çocukların ilgi ve alakalarını celp etmek $\sqrt{ }$ Etkin olmak

$\sqrt{ }$ Yönetme becerisi

$\sqrt{ }$ Donanımlı teçhizat

$\sqrt{ }$ Yeni usullerin tetkiki

$\sqrt{ }$ Resimde ve sanatta maharet 
Yöntem-teknik kategorisine göre, Beryl Parker'ın raporunda iyi bir vatandaşın sahip olması gereken niteliklerin, Dewey'den daha fazla olduğu görülmektedir. Her iki yabancı eğitim uzmanın raporunda, araç-gereç, deneyim, kitap, öğrenme ortamı, uygulama, etkin katılım, yöntem-teknik adlı temaların benzer olduğu tespit edilmiştir. Beryl Parker'ın raporunda, araç-gereç yani materyale daha çok vurgu yapıldığı yorumlanabilir. John Dewey ise uygulama ve deneyim ağırlıklı bir ortam olmasına yönelik görüşlerinin ağırlıkta olduğu saptanmıştır. Beryl Parker raporunda, yöntem ve tekniğe yönelik görüşlerinin fazla olmasının nedeni, ilkokula yönelik önerilerinin ağırlıkta olması ve temel eğitim çağındaki çocukların yaş dönemlerinden kaynaklanıyor olabilir.

\section{Sonuç, Tartışma ve Öneri}

Bilindiği gibi eğitimle ilgili tarihsel belgeler, dokümanlar, raporlar dönemin iyi, nitelikli ve donanımlı vatandaş özelliklerini belirtmeleri noktasında, son derece önemli bilgi kaynaklarıdır. Özellikle cumhuriyet döneminde, Batı'nın çağdaş eğitim değer ve uygulamaları daha yakından takip edilmeye başlanılmış, bu çerçevede birçok yabanc1 yabanc1 eğitim uzmanı, ülkemizde istihdam edilmiştir (Ortak, 2004). Bu bağlamda, bu araştırmanın sonuçlarına bakıldığında, Beryl Parker ve John Dewey'in raporlarında iyi vatandaş özelliklerini yansıtan temalara ulaşılmıştır. Her iki yabancı eğitim uzmanının raporlarında kodlamalar yapılmıştır. Bu kodlara dayalı olarak toplam 6 kategori meydana gelmiştir. Literatür incelendiğinde, Kızılay (2015), "iyi vatandaş özellikleri” hakkında yaptığı çalışmada 9 boyuta ulaşmıştır. Yeşilbursa (2015) 12 boyuta, Ersoy (2012) 3 boyuta, Osmanoğlu ve Öztürk (2012) 2 kategori, Kılınç ve Dere (2013), 2 boyut, Osmanoğlu, Adak ve Dereli (2013) 2 kategoriye ulaşmaları bu araştırmanın sonuçlarıyla tutarlı olduğu yorumlanabilir. Değerler kategorisinin sonuçlarına bakıldığında, her iki yabancı eğitim uzmanının raporunda sorumluluk, çalışkanlık, yardımlaşma adlı değerlere sıklıkla vurgu yapıldığı söylenebilir. Ancak Berly Parker raporunda, değerlere daha çok vurgu yaptı̆̆ 1 saptanmıştır. Öğretmen ve müfettiş kategorisinin sonuçları değerlendirildiğinde, her iki yabancı eğitim uzmanının raporunda en çok üzerinde durulan konu öğretmen yetiştirme ve müfettiş olduğu söylenebilir. Özellikle Türk eğitim sisteminin nitelikli, donanımlı ve iyi vatandaş yetiştirme noktasında, öğretmen ve denetleme mekanizmasının son derece önemli olduğu sonucuna ulaşılabilir. Beryl Parker ve Dewey raporlarında, eğitim programı kategorisine yönelik iyi vatandaş özelliklerinin en az yer aldığı kategori olmuştur (Dewey, 1939; Parker, 1939). Eğitim programı kategorisine yönelik niteliklerin az olmasının sebebi, John Dewey'in daha çok Türk eğitim sisteminin genel yapısı üzerine önerilerinin ağılıkta olmasından kaynaklanıyor olabilir. Beryl Parker ise raporunda, öğrenci, öğretmen ve okul konularına ağırlık vermiştir. Budak’a (2010, s. 130) göre, yabanc1 eğitim uzmanlarının raporlarında yer alan konulara bakıldığında, "ilköğretim süresinin uzatılması, okul yapımı, okullaşma çabaları ve okulların fiziki kapasitelerinin arttırılması, köy şartlarına uygun eğitim-öğretim, sınıfların donanımı ve koşulları, program, eğitim araçları, öğretim yöntem ve teknikleri, rehberlik programı ve uygulamaları", olduğunu belirterek bu çalışmada ortaya çıkan kategorileri destekler niteliktedir. Her iki yabancı eğitim uzmanının üzerinde sıklıkla durduğu konu, öğretmen yetiştirme olduğu söylenebilir. Çünkü bir ülkenin nitelikli ve donanımlı vatandaş yetiştirmede öğretmen etkin rol oynar. Özellikle öğretmen yetiştirilmesi noktasında, dönemin çağdaş pedagoji akımlarından faydalanılması ve daha kaliteli bir eğitim için önemli görüş ve öneriler sunulduğu belirtilmiştir (Şahin, 1996). Bu bağlamda, bu araştırmanın sonuçlarına dayalı olarak, Türkiye'ye gelen yabancı eğitim uzmanlarının eğitimle ilgili görüşleri, günümüz eğitimcilerin görüşleriyle karşılaştırılarak incelenebilir. Ayrıca raporlarında değer analizi yapılabilir. Türkiye'ye gelen yabancı eğitim uzmanlarının raporlarında yer alan görüş ve önerilerinin, Türk eğitim sistemi ve politikalarına ne derece etki ettiği araştırılabilir. 


\section{Extended Abstract}

\section{Introduction}

Regarding the elimination of the knowledge and technical deficiency experienced in the process of development and progress in the Republican period, foreign education experts were benefited from. In particular, the education specialists of modern countries were benefited from with the directives of Mustafa Kemal Atatürk in order to train qualified and well-equipped people. As is commonly known, education is an important issue for a country to develop in economic, cultural, social and political terms. It is expected that training humans to be equipped and qualified will eventually contribute to the development of the country. The concept of homeland has undergone a historical change in terms of approach and perception. It is seen that this concept brings with it a socio-cultural detail which can answer the question of "what type of a citizen?" In general, it is possible to say that the homeland is defined as the territory comprising the sovereignty and borders of the state. In particular, our education system has considered raising citizens who are respectful of human rights within the general aims of Turkish National Education (Doğan, 2004). In this context, since the concept of "citizen" has gained importance as the result of the developments from the past to the present day in the world, the importance of raising the type of people who will respond to the needs of society has emerged. As a result of this, it is possible to say that the education system has introduced the type of "good citizen" or "influential citizen" that it aims to educate (K1z1lay, 2016). Therefore, some historical papers, reports and documents are extremely important sources of information to understand the good citizen characteristics of the period. It is possible to say that the term good citizen has taken shaped based on the conditions, political structure and sociocultural factors of the relevant period. In this context, many foreign education experts who wrote reports on both good and qualified teachers and the general education system of the period were invited to Turkey in order to improve the quality of education in Turkey starting from the Republican period. In particular, between the years 1923 and 1960, that is the period of Ataturk- the National Leader (1923-1950), 79 experts, and during the Democratic Party (19501960) period, 44 experts, a total of 123 education experts came to Turkey (Şahin, 1996; Budak, 2010). Among these training experts, the report of John Dewey on the general education system and that of Beryl Parker on the first collection are just a few of these. When the content of the topics in the report of these two foreign education experts is examined in particular, it is possible to say that there are some merits about how a good citizen should be. When the relevant literature is examined, it is clearly seen that some studies on the impact of foreign experts in teacher education (Şahin, 1996), the foreign experts during the Atatürk period (Ortak, 2004), the perception of a good citizen, citizen education, good people good citizens, a good citizen for me, a good citizen in textbooks and good citizen perception of the students (Dynneson, 1992; Prior, 1999; Civek, 2008; K1lınç, 2014; Ersoy, 2012; Osmanoğlu and Öztürk, 2012; Yeşilbursa, 2015; Kızllay, 2015) were carried out. In fact, it was found that the studies on what good citizens were like in the historical documents and reports related to education system were non-existent in the literature review we performed. For this reason, the main problem of the present study is to reveal the good citizen perception in the reports of John Dewey and Beryl Parker, two of the foreign education experts in the Republican era.

\section{Method}

Especially the historical documents, textbooks and educational programs in the field of education mainly focus on how a citizen should be. In this context, the main objective of the study is to identify the good citizen perception in the report of John Dewey and Beryl Parker, two foreign education experts, who came to Turkey during the Republican era. It is possible to say that qualitative research tries to describe some events as the way they were in the past by going back to the past in an attempt to better understand some issues (Karasar, 2012). Qualitative researchers try to understand how people interpret their experiences, how they build up their worlds, and how they make sense of their experience (Merriam, 2013). Therefore, in order to contribute to the definition and limitation of the problem, the investigation can be placed within a historical perspective and the relevant information can be connected to each other (Balc1, 2010). In this context, since this study examines the good citizen perception based on historical reports, document analysis, one of the qualitative research methods, has been used as data collection tool in this study. The reports used as a data source in the study are presented below.

- Dewey, J. (1939). The Report on the Ministry of Education of Turkey, Istanbul: Government Printing Office

- Parker, B. (1939). The Report on First Education in Turkey, Istanbul: Government Printing Office

The data obtained by the method in accordance with the purpose of the study were analyzed based on content analysis. When analyzing the data, meaning is exported. In this context, it includes integrating, reducing and 
interpreting what people say, what the researcher sees and what she reads (Merriam, 2013). Content analysis encodes and specifies the content, themes and patterns of text data within the systematic classification process (Yıldırım \& Şimşek, 2012). Therefore, category creation is actually a data analysis. In particular, it is possible to say that the notes, interpretations and observations obtained during the period we read the document are a type of encodings called data components (Merriam, 2013). As a result of these encodings, the categories create conceptual elements that cover many unique examples and relate to each other (Merriam, 2013, p, 173).

\section{Findings}

As a result of the analyses carried out in this study, some codes were generated and as a result categories based on these codes were formed.

1. Values

2. Teacher and Inspector

3. Student

4. School

5. Education program

6. Method-Technique

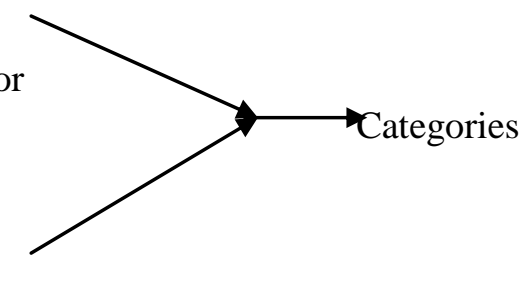

In the Values section, the value codes available in Beryl Parker and John Dewey's reports that reflected good citizen characteristics were included. It is possible to say that the values such as responsibility, diligence, support, capability, cooperation were mentioned. It is clearly seen that there was more emphasis on values especially in Beryl Parker's report. The reason for this is that clearly Beryl Parker's report mostly included recommendations for primary schools and took the age of the children into consideration in terms of teaching some basic values.

In the category of teachers and inspectors, it is possible to say that the subject most frequently emphasized in the report of both of the foreign education experts was teacher training and inspectors. It can be interpreted that the teachers and inspection mechanism were crucially important especially concerning the Turkish education system to raise qualified, well-equipped and good citizens. In Beryl Parker's report, it was found that she emphasized the issues such as qualified teachers, sense of mission, effective inspection and collaboration skills. In John Dewey's report, on the other hand, it can be said that themes such as experiences of the teacher, training inspectors, love of the profession and practice of the profession and collaboration were addressed. It can be interpreted that the collaboration, inspector mechanism, sense of mission, unity and solidarity and counselling were common in the reports of both of the foreign education experts.

In the student category, it is possible to say that Beryl Parker and John Dewey's reports included findings that reflected good citizen qualities. In Beryl Parker's report, it can be said that there was emphasis on the themes such as student education, discipline, capability, individual differences, willing and hardworking student. John Dewey's report, on the other hand, discussed themes such as experiencing, capability, qualified and well-equipped citizens, discipline and success. In the report of both of the foreign education experts especially, it was revealed that the issues such as the need to provide quality education to the students, their capabilities, their diligence, their participation in artistic activities were similar. While Beryl Parker, in her report, emphasized student individuality, John Dewey emphasized the socialization of the student in his report.

Regarding the school category, both of the foreign education experts stated how important the school was in raising good and qualified citizens. In the school category of Beryl Parker and John Dewey, it is possible to say that the school's facilities and equipment focused on school-community relationship. It can be interpreted that it was important that John Dewey, in particular, emphasized the association between school, student and real life. It is because a good and qualified citizen is the one who applies the knowledge learned at school in life and acts in a way to find solutions to the existing problems in life. Therefore, it is possible to say that the school should have a basic philosophy, purpose and goal in raising citizens. In her report, it was revealed that Beryl Parker expressed her opinions about the physical structure of the school and emphasized the use of school efficiently, that is economically. In his report John Dewey, on the other hand, put forward ideas that the school should be the center of real life and experience.

In the education program category, it was found that in her report, Beryl Parker emphasized the themes such as the quality of education, a good and calculated program and citizenship education. In John Dewey's report, on the other hand, it can be interpreted that issues such as continuity of the program, innovation in the program, calculated and guiding program were mentioned. It can be said that in the reports of both of the foreign educational experts, a calculated program, an applied program was emphasized. In Beryl Parker and John Dewey's report, the education program category was the category in which the best citizen characteristics were the least. Particularly, the reason for the lack of codes for this category might be because John Dewey had mostly recommendations for teacher training and the general education system. Moreover, since Beryl Parker's report was on the themes of students, schools and 
teachers in the primary education system, it is possible to say that the themes related to education curricula were emphasized less.

Regarding the category of method-technique, in terms of the characteristics that a good citizen should have, it is clearly seen that the codes included in the report of Beryl Parker were more than those of John Dewey. In the report of both of the foreign education experts, it can be said that the themes such as equipment, experiences, books, learning environment, practice, active participation, method-technique were similar. In Beryl Parker's report, it is seen that equipment, that is the material was emphasized more. It was found that John Dewey emphasized an environment of practice and experience. In Beryl Parker's report, the reason that her opinions on the method and technique were predominant may be based on the fact that the age of children in basic education was taken into consideration regarding her suggestions for primary education.

\section{Discussion and Conclusion}

As it is commonly known, historical papers, documents and reports related to education are very important sources of information about reflecting the characteristics of the good citizen desired to be raised during the relevant period. Especially in the Republican period, the modern educational values and practices of the West started to be followed more closely and in this context, many foreign education experts were employed in our country (Ortak, 2004). In this context, when the results of this study are examined, themes reflecting the characteristics of good citizens were identified in the reports of Beryl Parker and John Dewey. There were codes in the reports of both of the foreign education experts. Based on these codes, a total of 6 categories emerged. When the literature is examined, the fact that Kizılay (2015) created 9 dimensions in his study on "good citizen characteristics", Yeşilbursa (2015) generated 12 dimensions, Ersoy (2012) 3 dimensions, Osmanoğlu and Özturk (2012) 2 categories, Kılınç and Dere (2013), Osmanoğlu, Adak and Dereli (2013) 2 categories can be interpreted as consistent with the results of the present study. When the results of the values category are examined, it is possible to say that the values such as responsibility, diligence, and cooperation were frequently emphasized in the reports of both of the foreign education experts. However, it was found that Beryl Parker's report emphasized values more. When the results of the teacher and inspector category are evaluated, it is possible to say that the subjects that both of the foreign education experts emphasized the most were teacher training and inspectors. It was concluded that teachers and inspection mechanism were crucially important especially concerning the Turkish education system to raise qualified, well-equipped and good citizens. In the reports of Beryl Parker and John Dewey, the category of education program was the category with the least characteristics of a good citizen (Dewey, 1939; Parker, 1939). The reason for the lack of qualities for the curriculum might be due to the fact that John Dewey's recommendations mostly aimed at the general structure of the Turkish education system. Beryl Parker, on the other hand, focused predominantly on the issues of students, teachers and school subjects regarding the structure of primary school education. 


\section{Kaynakça/References}

Bal, H. (1991). 1924 Raporunun Türk eğitimine etkileri ve John Dewey'in eğitim felsefesi. İstanbul: Aydınlar Matbaası.

Budak, Ç. (2010). Türkiye'de ilkokul programları ve yabancı uzmanların ilkokul programlarına olan etkisi (19231960). (Yayınlanmamış yüksek lisans tezi), Adnan Menderes Üniversitesi, Aydın.

Civek, B. D. (2008). Yeni sosyal bilgiler 4. ve 5. sınıf programlarında vatandaşlık eğitimi. (Yayınlanmamış Yüksek Lisans Tezi). Gazi Üniversitesi, Ankara.

Dewey, J. (1939) Türkiye maarifi hakkında rapor. İstanbul: Maarif Basımevi.

Doğan, İ (2004). Modern toplumda vatandaşlık demokrasi ve insan hakları. Ankara: PegemA Yayıncılık.

Karasar, N. (2012). Bilimsel araştırma yöntemi. Ankara: Nobel Yayınları.

Kılınç, E. (2014). Does good citizen consider envirenment? The correlation between characteristic of good citizen and envirenmental attitudes amongst pre-service social studies teachers. Journal of Environmental Protection and Ecology, 15(3A), 1434-1441.

Merriam, S. B. (2013). Nitel araştırma desen ve uygulama için bir rehber. Ankara: Nobel Yayınc1lık.

Ortak, Ş. (2004). Atatürk dönemi eğitim politikalarında yabancı uzman raporlarının etkileri. (Yayımlanmamış Doktora Tezi), Atatürk Üniversitesi, Erzurum.

Osmanoğlu, A. E., Adak, N., \& Dereli, E. (2013). 6. sınıf sosyal bilgiler ders kitabında vatandaşlık algısı. Bingöl Üniversitesi Sosyal Bilimler Enstitüsü Dergisi, 3(5), 63.

Osmanoğlu, A. E., \& Öztürk, C. (2012). Türkiye ve Mısır sosyal bilgiler ders kitaplarında vatandaşlık algısının karş1laştırmalı analizi. Pegem Ĕgitim ve Öğretim Dergisi, 2(3), 44-60

Parker, B. (1939). Türkiye'de ilk tahsil hakkında rapor. İstanbul. Devlet Basımevi.

Prior, W. (1999). What it means to be a "good citizen" in Australia. Social Education, 27(2), 215-247

Şahin, M. (1996). Türkiye'de öğretmen yetişstirme uygulamalarında yabancı uzmanların yeri (1923-1960). (Yayımlanmamış Doktora Tezi), Dokuz Eylül Üniversitesi, İzmir.

Şimşek, H., \& Yıldırım, A. (2012). Sosyal bilimlerde nitel araştırma yöntemleri. Ankara: Seçkin Yayınları.

Yeşilbursa, C. C. (2015). Turkish pre-service social studies teachers' perceptions of "good" cizitezship. Academic Journals, 10(5), 634-640. 